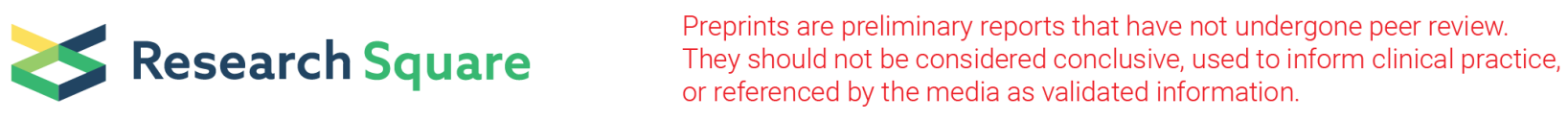

\title{
CLS, PLS and PCR Methods in Different Sets of Data for Simultaneous Determination of Paracetamol and Orphenadrine Citrate in Their Combined Pharmaceutical Dosage Forms
}

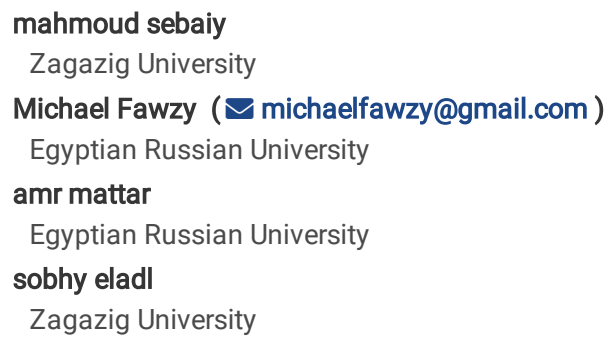




\begin{abstract}
Three simple, specific, accurate and precise chemometric methods have been developed for the analysis of paracetamol and orphenadrine citrate in their mixture form without prior separation. CLS, PLS and PCR methods were used for simultaneous determination of paracetamol and orphenadrine citrate by using different sets of data in which better results were produced. The validity of these chemometrics has been carried out by using 8 synthetic mixtures for determination of the power of prediction for each method. Latent variable number is different from one model to another concurrent with changing the set of data. PRESS (predicted residual error sum of squares) and RMSEP (Root mean square error of prediction) were used for the comparison between different methods and for determination the predictive power of each set of data. Statistical comparison between the proposed chemometric methods was also performed.
\end{abstract}

\title{
1. Introduction
}

Paracetamol (PAR); N-(4-Hydroxyphenyl)acetamide (Fig. 1) is centrally and peripherally acting analgesic drug that can be used to treat non-inflammatory conditions [1]. Orphenadrine citrate (ORP); ( \pm )-N,N-Dimethyl-2-[(o-methyl-a-phenylbenzyl)oxy]ethylamine citrate (Fig. 1) is a centrally acting skeletal muscle relaxant which prevents impulses of the somatic nerves from being generated by inhibiting a specific neurons in the nervous system. The combination of an analgesic drug and a skeletal muscle relaxant is better than single agents alone as the antinociceptive effect of PAR is prolonged and increased when combined with ORP [1].

Please insert Figure 1

The literature survey demonstrated that several methods have been carried out for the analysis of PAR \& ORP in their pharmaceutical formulation or biological fluids. PAR \& ORP were determined in their pharmaceutical formulation by using spectrophotometric methods [1-6], HPLC methods [7-9], TLC and microemulsion HPLC method [10], square wave voltammetric method [11] and capillary electrophoresis method [12]. Several methods have been reported for determination of PAR alone in biological matrix including spectrophotometric methods [13-16], HPLC methods [17-21], HPTLC method [22], GC method [23] and voltammetric methods [24-26]. On the other hand, only chromatographic methods have been reported for determination of ORP alone in biological matrix including HPLC method [27] and GC methods [28-30]. In addition, there is only one reported method for simultaneous determination of PAR \& ORP in human serum by using HPLC method [31].

The aim of this work is to develop simple, easy, economic, accurate, fast and non-complicated chemometric methods with different sets of data for the determination of PAR \& ORP in their pharmaceutical formulations without any interference and to compare the results of all sets of data to determine the one set with the most powerful predictive power. Also, these developed chemometric methods are simpler and more accurate in calculations and results than previously reported methods. The obtained results have been statistically compared and interpreted.

\section{Experimental}

\subsection{Apparatus}

JASCO dual beam UV-visible spectrophotometer (Japan) model V-630, connected to a compatible computer (ACER) with spectra manager II software was used. The spectral slit width is $2 \mathrm{~nm}$ with scan speed up to $8000 \mathrm{~nm} / \mathrm{min}$. At room temperature, $1 \mathrm{~cm}$ quartz cell was used for all measurement over wavelength range of $200-400 \mathrm{~nm}$.

\subsection{Software}

Matlab® 7.0.1. Software program was used to carry out chemometric analysis. Also, PASW statistics $18 \circledast$ software program was used for statistical analysis.

\subsection{Materials and Reagents}

\subsubsection{Pure standard materials}

PAR \& ORP were provided kindly by Egyptian International Pharmaceutical Industries Co. (EIPICO), located in 10th of Ramadan city, Egypt. Their purities were reported to be $99.50 \% \& 99.70 \%$, respectively.

\subsubsection{Pharmaceutical formulation}

Orphenadrine plus ${ }^{\circledR}$ tablets (Alexandria Co., Egypt) were purchased from the market (labeled to contain Orphenadrine citrate $50 \mathrm{mg}$ and Paracetamol 450 $\mathrm{mg})$.

\subsubsection{Analytical Solvents}

HPLC grade Methanol was purchased from, Merck (Darmstadt Germany). Spectral measurements have been carried out using $90 \%$ Methanol (methanol: Distilled water, 9:1).

\subsubsection{Standard solutions preparation}

Standard PAR \& ORP stock solutions $(1 \mathrm{mg} / \mathrm{mL})$ have been prepared in $90 \%$ methanol. PAR working standard solutions $(40 \mu \mathrm{g} / \mathrm{mL})$ have been prepared in $90 \%$ methanol while ORP working standard solutions $(50 \mu \mathrm{g} / \mathrm{mL}$ ) have been prepared by diluting the stock solution using $90 \%$ methanol. 25 mixture solutions 
of PAR \& ORP in the concentration range of $4-20 \mu \mathrm{g} / \mathrm{mL}$ for PAR and $5-50 \mu \mathrm{g} / \mathrm{mL}$ for ORP in the same solvent have been symmetrically prepared from the previous stock solutions respectively and the concentration set design was demonstrated in Fig. 2.

\subsection{Calibration set}

17 synthetic mixtures in the range of $4-20 \mu \mathrm{g} / \mathrm{mL}$ for PAR and $5-50 \mu \mathrm{g} / \mathrm{mL}$ for ORP were prepared as a training set according to the multifactor and the multilevel design in $10 \mathrm{~mL}$ volumetric flasks. UV absorption spectra in its raw form and in its manipulated spectral data sets were used to construct the chemometric models of CLS, PLS and PCR.

\subsection{Prediction set}

8 synthetic mixtures in same range of calibration set for PAR \& ORP were prepared as a validation set according to the multifactor and the multilevel design in $10 \mathrm{~mL}$ volumetric flasks to evaluate the accuracy and precision of the constructed models.

\subsection{Data preprocessing}

Absorption spectra were scanned from 200 to $400 \mathrm{~nm}$ while the region 200-215 nm was neglected to avoid the noise. Calculations have been carried out from 215-275 nm which gave the best results. First and Second derivatives of the absorption spectra were processed before building some models to assess their effect on the validation of the analysis. Ratio spectra were also calculated using divisors of PAR (8ug) and ORP (20ug) separately, but the analysis was then continued by using PAR (8ug) as a divisor and its ratio derivatives due to its more accurate and better results than ORP.

\subsection{Application to pharmaceutical tablets}

10 Tablets of Orphenadrine plus ${ }^{\circledR}$ were weighed and crushed then an amount equivalent to $50 \mathrm{mg}$ PAR and $5.55 \mathrm{mg}$ ORP in each tablet was transferred into a $50 \mathrm{~mL}$ volumetric flask and diluted with $90 \%$ methanol as follow: First, $30 \mathrm{~mL}$ of $90 \%$ methanol were added and sonicated then dilution with $70 \mathrm{~mL}$ of $90 \%$ methanol was carried out to the $50 \mathrm{~mL}$ mark and then filtered. Second, $10 \mathrm{~mL}$ of prepared solution was transferred to a $100 \mathrm{~mL}$ volumetric flask to give a concentrations equivalent to $100 \mu \mathrm{g} / \mathrm{mL}$ (for PAR) and $11.11 \mu \mathrm{g} / \mathrm{mL}$ (for ORP). Third, other further dilutions were carried out in $10 \mathrm{~mL}$ volumetric flasks and treated in a similar way as described in the proposed methods.

\section{Results And Discussion}

\subsection{Method Optimization}

Three simple chemometric methods CLS, PLS and PCR have been used for simultaneous determination of PAR \& ORP in their pharmaceutical dosage form. Absorption spectra in its raw form and in its manipulated forms (First derivative, Second derivative, Ratio spectra, First derivative of ratio spectra and Second derivative of ratio spectra) as different sets of data (Fig. 3) were used to build CLS, PLS and PCR models in the range of 215-275 nm.

Figure 4 displays the absorption spectra of Zero, First derivative, Second derivative, Ratio spectra, First derivative of ratio spectra and Second derivative of ratio spectra of PAR, ORP and their mixture. CLS, PLS and PCR models were constructed by using a calibration set consisting different ratios of PAR \& ORP as shown in Table 1.

Table 1 Chemometric design for calibration and validation sets for PAR \& ORP.

\begin{tabular}{|lllllllll|}
\hline Set & \multicolumn{2}{l}{ Calibration set } & Set & \multicolumn{2}{l}{ Calibration set } & Set & \multicolumn{2}{c|}{ Validation set } \\
Mix No. & PAR & ORP & Mix No. & PAR & ORP & Mix No. & PAR & ORP \\
\hline C1 & 7 & 7 & C10 & 9 & 9 & C1 & 7 & 5 \\
\hline C 2 & 9 & 9 & C11 & 9 & 5 & C 2 & 5 & 5 \\
C 3 & 9 & 7 & C12 & 5 & 8 & C 3 & 9 & 6 \\
\hline C 4 & 7 & 6 & C13 & 5 & 7 & C 4 & 6 & 9 \\
\hline C 5 & 6 & 6 & C14 & 7 & 8 & C 5 & 9 & 8 \\
\hline C6 & 6 & 8 & C15 & 8 & 8 & C 6 & 8 & 5 \\
\hline C 7 & 8 & 9 & C16 & 6 & 5 & C 7 & 8 & 6 \\
\hline C 8 & 8 & 7 & C17 & 6 & 7 & C 8 & 5 & 6 \\
\hline C 9 & 7 & 9 & & & & & & \\
\hline
\end{tabular}

Cross-validation and Scaling were carried out on the calibration set through leaving out one at a time cross-validation and mean center scaling for PLS and PCR models. The number of latent variables is varied from one model to another. Wavelength range from 215 to $275 \mathrm{~nm}$ with $\Delta \lambda=0.1 \mathrm{~nm}$ for Zero, First and Second derivative and with $\Delta \lambda=1 \mathrm{~nm}$ for Ratio spectra and its derivatives was used in all measurements as it was found to give more precise and more accurate results. Parameters used in the construction of PLS and PCR models were demonstrated in Table 2. 
Table 2

\begin{tabular}{|lllllllll|}
\hline Set & \multicolumn{2}{l}{ Calibration set } & Set & \multicolumn{2}{c}{ Calibration set } & Set & \multicolumn{2}{c|}{ Validation set } \\
\hline Mix No. & PAR & ORP & Mix No. & PAR & ORP & Mix No. & PAR & ORP \\
\hline C1 & 7 & 7 & C10 & 9 & 9 & C1 & 7 & 5 \\
\hline C 2 & 9 & 9 & C11 & 9 & 5 & C 2 & 5 & 5 \\
\hline C 3 & 9 & 7 & C12 & 5 & 8 & C 3 & 9 & 6 \\
\hline C 4 & 7 & 6 & C13 & 5 & 7 & C 4 & 6 & 9 \\
C 5 & 6 & 6 & C14 & 7 & 8 & C 5 & 9 & 8 \\
\hline C 6 & 6 & 8 & C15 & 8 & 8 & C 6 & 8 & 5 \\
\hline C 7 & 8 & 9 & C16 & 6 & 5 & C 7 & 8 & 6 \\
\hline C 8 & 8 & 7 & C17 & 6 & 7 & C 8 & 5 & 6 \\
\hline C 9 & 7 & 9 & & & & \\
\hline Chemometric parameters used for construction of PLS \& PCR models. & \\
\hline
\end{tabular}

The optimal number of latent variables is different from one model to another and is demonstrated for PLS in Fig. 5 and for PCR in Fig. 6.

\subsection{Method validation}

The Validation of CLS, PLS and PCR models were calculated by the analysis of their predictive ability on the validation (prediction) set for assessment of the accuracy and precision. The predicted values and actual values of both calibration and validation sets were compared then predicted residual error sum of squares (PRESS) and root mean square error of prediction (RMSEP) were calculated for various models as follow:

PRESS $=$ Calculate the difference between expected values and predicted values for all the samples and square them then sum them together .

RMSEP = Divide PRESS by number of mixtures and calculate the root of the resulted value.

Results for different chemometric methods are shown in Tables 3,4,5.

Table 3

\begin{tabular}{|lllll|}
\hline Method & Range $(\mathrm{nm})$ & Interval $(\mathrm{nm})$ & Scaling & Cross Validation \\
\hline Zero & $215-275$ & 0.1 & Mean center & Leave one out \\
\hline First derivative & $215-275$ & 0.1 & Mean center & Leave one out \\
\hline Second derivative & $215-275$ & 0.1 & Mean center & Leave one out \\
\hline Ratio spectra & $215-275$ & 1 & Mean center & Leave one out \\
Ratio derivative & $215-275$ & 1 & Mean center & Leave one out \\
\hline Ratio second derivative & $215-275$ & 1 & Mean center & Leave one out \\
\hline Results obtained From CLS models for determination of PAR \& ORP in calibration and validation sets. \\
\hline
\end{tabular}

Table 4

\begin{tabular}{|c|c|c|c|c|c|c|c|c|c|c|c|c|c|}
\hline \multicolumn{2}{|c|}{ Spectra order } & \multicolumn{2}{|l|}{ Zero } & \multicolumn{2}{|c|}{ First derivative } & \multicolumn{2}{|c|}{ Second derivative } & \multicolumn{2}{|c|}{ Ratio spectra } & \multicolumn{2}{|c|}{ Ratio derivative } & \multicolumn{2}{|c|}{$\begin{array}{l}\text { Ratio 2nd } \\
\text { derivative }\end{array}$} \\
\hline CLS & Parameter & PAR & ORP & PAR & ORP & PAR & ORP & PAR & ORP & PAR & ORP & PAR & ORP \\
\hline \multirow{3}{*}{$\begin{array}{l}\text { Calibration } \\
\text { set }\end{array}$} & Mean & 99.39 & 99.67 & 99.74 & 100.18 & 102.90 & 102.90 & 99.27 & 99.82 & 103.05 & 100.14 & 102.47 & $100.8=$ \\
\hline & PRESS & 1.9331 & 10.0823 & 0.2146 & 1.0009 & 10.9490 & 15.1091 & 3.1221 & 6.9166 & 140.6719 & 1.8254 & 56.6871 & $3.602 \epsilon$ \\
\hline & RMSE & 0.3372 & 0.7701 & 0.1123 & 0.2426 & 0.8025 & 0.9427 & 0.4285 & 0.6379 & 2.8766 & 0.3277 & 1.8261 & $0.460 \approx$ \\
\hline \multirow{3}{*}{$\begin{array}{l}\text { Validation } \\
\text { set }\end{array}$} & Mean & 99.03 & 100.55 & 99.89 & 104.32 & 96.94 & 117.86 & 98.67 & 100.93 & 108.78 & 101.45 & 105.83 & 102.75 \\
\hline & PRESS & 0.3072 & 2.5266 & 0.1291 & 1.3856 & 22.5319 & 34.0142 & 0.5022 & 2.0533 & 33.8073 & 1.3540 & 18.8684 & $2.002 C$ \\
\hline & RMSE & 0.1960 & 0.5620 & 0.1270 & 0.4162 & 1.6782 & 2.0620 & 0.2505 & 0.5066 & 2.0557 & 0.4114 & 1.5358 & 0.5002 \\
\hline
\end{tabular}

Results obtained From PLS models for determination of PAR \& ORP in calibration and validation sets. 
Table 5

\begin{tabular}{|c|c|c|c|c|c|c|c|c|c|c|c|c|c|}
\hline \multirow{2}{*}{$\begin{array}{l}\text { Spectra order } \\
\text { PLS }\end{array}$} & \multirow[b]{2}{*}{ Parameter } & \multirow{2}{*}{$\begin{array}{l}\text { Zero } \\
\text { PAR }\end{array}$} & \multirow[b]{2}{*}{ ORP } & \multicolumn{2}{|c|}{ First derivative } & \multicolumn{2}{|c|}{ Second derivative } & \multicolumn{2}{|c|}{ Ratio spectra } & \multicolumn{2}{|c|}{ Ratio derivative } & \multicolumn{2}{|c|}{$\begin{array}{l}\text { Ratio 2nd } \\
\text { derivative }\end{array}$} \\
\hline & & & & PAR & ORP & PAR & ORP & PAR & ORP & PAR & ORP & PAR & ORP \\
\hline \multirow{3}{*}{$\begin{array}{l}\text { Calibration } \\
\text { set }\end{array}$} & Mean & 100.02 & 100.02 & 100.03 & 100.01 & 100.08 & 100.03 & 100.01 & 100.01 & 100.06 & 100.00 & 100.17 & 100.10 \\
\hline & PRESS & 0.0920 & 0.1342 & 0.1016 & 0.1080 & 0.4750 & 0.2267 & 0.0852 & 0.1398 & 0.9250 & 0.1590 & 1.5352 & 0.5594 \\
\hline & RMSEP & 0.0736 & 0.0888 & 0.0773 & 0.0797 & 0.1671 & 0.1155 & 0.0708 & 0.0907 & 0.2333 & 0.0967 & 0.3005 & 0.1814 \\
\hline \multirow{3}{*}{$\begin{array}{l}\text { Validation } \\
\text { set }\end{array}$} & Mean & 100.70 & 100.58 & 101.10 & 105.96 & 101.55 & 123.01 & 100.75 & 101.10 & 100.93 & 100.83 & 113.28 & 103.68 \\
\hline & PRESS & 0.1524 & 1.0837 & 0.2410 & 1.9214 & 19.8164 & 25.2057 & 0.1778 & 1.3162 & 0.8381 & 1.5144 & 12.5025 & 2.4698 \\
\hline & RMSEP & 0.1380 & 0.3681 & 0.1735 & 0.4901 & 1.5739 & 1.7750 & 0.1491 & 0.4056 & 0.3237 & 0.4351 & 1.2501 & 0.5556 \\
\hline
\end{tabular}

Results obtained From PCR models for determination of PAR \& ORP in calibration and validation sets.

\subsubsection{For CLS}

Zero absorption spectra and Ratio spectra can be used for determination of PAR only and not applicable for ORP. First derivative spectra can be used for determination of both PAR \& ORP with the most powerful prediction for both drugs (least RMSEP for both calibration and validation sets). On the other hand, Ratio derivative and Ratio second derivative spectra may be used for determination of ORP only and can't be used for determination of PAR. However, Second derivative spectra can't be beneficial for determination of both drugs.

\subsubsection{For PLS}

Zero absorption spectra, First derivative spectra, Ratio spectra and Ratio derivative spectra can be used for determination of both PAR \& ORP in which First derivative has the most powerful prediction for ORP while Zero \& Ratio spectra have the most powerful prediction for PAR (It is better to use Zero absorption spectra as there is no need for extra processing). On the other hand, Second derivative spectra and Ratio second derivative spectra can't be used for determination of both drugs at all.

\subsubsection{For PCR}

Zero absorption spectra, Ratio spectra and Ratio derivative spectra can be applicable for determination of both drugs in which Zero absorption spectra has the most powerful prediction for both PAR \& ORP. Also, First derivative spectra may be used for determination of PAR only and can't be used for determination of ORP. On the other hand, Second derivative spectra and Ratio second derivative can't be used for determination of both PAR \& ORP.

Although the Raw data set (Zero spectra) is the simplest method but manipulation of the spectra to give different sets of data makes a great differences and may improves the results. Although the ratio spectra set of data requires an extra-processing before carrying out the measurements, First and Second derivative of ratio spectra sets of data requires more manipulation as it needs more extra process than the ratio spectra.

\subsection{Application to Pharmaceutical Tablets}

The proposed chemometric methods were successfully applied for simultaneous determination of PAR and ORP in Orphenadrine plus ${ }^{\circledR}$ tablets. The results were acceptable with a great agreement in respect with labeled concentrations. The standard addition technique was carried out for accuracy and demonstrated that excipients interference was not observed (Tables 6,7, 8).

Table 6

\begin{tabular}{|c|c|c|c|c|c|c|c|c|c|c|c|c|c|}
\hline \multirow{2}{*}{$\begin{array}{l}\text { Spectra orde } \\
\text { PLS }\end{array}$} & \multirow[b]{2}{*}{ Parameter } & \multirow{2}{*}{$\begin{array}{l}\text { Zero } \\
\text { PAR }\end{array}$} & \multirow[b]{2}{*}{ ORP } & \multicolumn{2}{|c|}{ First derivative } & \multicolumn{2}{|c|}{ Second derivative } & \multicolumn{2}{|c|}{ Ratio spectra } & \multicolumn{2}{|c|}{ Ratio derivative } & \multicolumn{2}{|l|}{$\begin{array}{l}\text { Ratio 2nd } \\
\text { derivative }\end{array}$} \\
\hline & & & & PAR & ORP & PAR & ORP & PAR & ORP & PAR & ORP & PAR & ORP \\
\hline \multirow{3}{*}{$\begin{array}{l}\text { Calibration } \\
\text { set }\end{array}$} & Mean & 100.02 & 100.02 & 100.02 & 100.16 & 102.12 & 102.00 & 100.02 & 100.03 & 100.31 & 100.08 & 100.34 & 100.04 \\
\hline & PRESS & 0.0924 & 0.1371 & 0.0948 & 1.3985 & 15.6814 & 16.6506 & 0.0898 & 0.1647 & 3.7990 & 0.5882 & 3.4579 & 0.3150 \\
\hline & RMSEP & 0.0737 & 0.0898 & 0.0747 & 0.2868 & 0.9604 & 0.9897 & 0.0727 & 0.0984 & 0.4727 & 0.1860 & 0.4510 & 0.1361 \\
\hline \multirow{3}{*}{$\begin{array}{l}\text { Validation } \\
\text { set }\end{array}$} & Mean & 100.70 & 100.58 & 101.17 & 106.82 & 103.87 & 121.31 & 100.76 & 101.12 & 100.34 & 101.37 & 116.35 & 104.22 \\
\hline & PRESS & 0.1526 & 1.0827 & 0.2431 & 2.5506 & 19.4536 & 24.8743 & 0.1783 & 1.2955 & 1.3670 & 1.1259 & 14.8215 & 2.2239 \\
\hline & RMSEP & 0.1381 & 0.3679 & 0.1743 & 0.5646 & 1.5594 & 1.7633 & 0.1493 & 0.4024 & 0.4134 & 0.3752 & 1.3611 & 0.5272 \\
\hline
\end{tabular}

Pharmaceutical preparation (Orphenadrine Plus ${ }^{\circledR}$ tablets) and standard addition results from using CLS chemometric models. 
Table 7

\begin{tabular}{|c|c|c|c|c|c|c|c|c|c|c|c|c|c|}
\hline \multirow{2}{*}{$\begin{array}{l}\text { Spectra order } \\
\text { CLS }\end{array}$} & \multirow[b]{2}{*}{ Parameter } & \multirow{2}{*}{$\begin{array}{l}\text { Zero } \\
\text { PAR }\end{array}$} & \multirow[b]{2}{*}{ ORP } & \multicolumn{2}{|c|}{ First derivative } & \multicolumn{2}{|c|}{$\begin{array}{l}\text { Second } \\
\text { derivative }\end{array}$} & \multicolumn{2}{|c|}{ Ratio spectra } & \multicolumn{2}{|c|}{ Ratio derivative } & \multicolumn{2}{|c|}{$\begin{array}{l}\text { Ratio 2nd } \\
\text { derivative }\end{array}$} \\
\hline & & & & PAR & ORP & PAR & ORP & PAR & ORP & PAR & ORP & PAR & ORP \\
\hline \multirow{2}{*}{$\begin{array}{l}\text { Pharmaceutical } \\
\text { formulation }\end{array}$} & Mean & 100.07 & 102.13 & 99.79 & 100.11 & 104.83 & 109.00 & 99.44 & 105.77 & 83.69 & 101.50 & 109.96 & 100.33 \\
\hline & SD & 0.91 & 1.88 & 0.50 & 0.51 & 8.62 & 3.00 & 1.11 & 5.18 & 35.02 & 1.29 & 7.59 & 1.94 \\
\hline \multirow{2}{*}{$\begin{array}{l}\text { Standard addition } \\
\text { technique }\end{array}$} & Mean & 100.34 & 102.42 & 99.03 & 99.94 & 102.20 & 110.30 & 98.71 & 109.00 & 76.34 & 101.24 & 109.82 & 100.59 \\
\hline & SD & 0.82 & 1.20 & 0.50 & 0.86 & 10.68 & 4.28 & 0.51 & 8.95 & 27.91 & 1.51 & 9.38 & 1.72 \\
\hline
\end{tabular}

Pharmaceutical preparation (Orphenadrine Plus ${ }^{\circledR}$ tablets) and standard addition results from using PLS chemometric models.

Table 8

\begin{tabular}{|c|c|c|c|c|c|c|c|c|c|c|c|c|c|}
\hline \multirow{2}{*}{$\begin{array}{l}\text { Spectra order } \\
\text { CLS }\end{array}$} & \multirow[b]{2}{*}{ Parameter } & \multirow{2}{*}{$\begin{array}{l}\text { Zero } \\
\text { PAR }\end{array}$} & \multirow[b]{2}{*}{ ORP } & \multicolumn{2}{|c|}{ First derivative } & \multicolumn{2}{|c|}{$\begin{array}{l}\text { Second } \\
\text { derivative }\end{array}$} & \multicolumn{2}{|c|}{ Ratio spectra } & \multicolumn{2}{|c|}{ Ratio derivative } & \multicolumn{2}{|c|}{$\begin{array}{l}\text { Ratio 2nd } \\
\text { derivative }\end{array}$} \\
\hline & & & & PAR & ORP & PAR & ORP & PAR & ORP & PAR & ORP & PAR & ORP \\
\hline \multirow{2}{*}{$\begin{array}{l}\text { Pharmaceutical } \\
\text { formulation }\end{array}$} & Mean & 100.01 & 100.67 & 98.90 & 100.12 & 104.14 & 136.36 & 100.29 & 99.73 & 100.41 & 99.62 & 116.33 & 106.43 \\
\hline & SD & 0.06 & 1.88 & 0.40 & 0.15 & 21.59 & 12.56 & 0.30 & 1.59 & 0.29 & 1.97 & 18.46 & 3.99 \\
\hline \multirow{2}{*}{$\begin{array}{l}\text { Standard addition } \\
\text { technique }\end{array}$} & Mean & 100.53 & 100.25 & 99.40 & 100.47 & 107.68 & 110.18 & 100.52 & 99.89 & 99.46 & 99.85 & 107.97 & 104.85 \\
\hline & SD & 0.47 & 1.95 & 0.66 & 0.16 & 11.29 & 38.42 & 0.44 & 1.97 & 1.38 & 1.98 & 10.28 & 8.31 \\
\hline
\end{tabular}

\subsection{Statistical Analysis}

Statistical analysis of these proposed methods has been done out by One-way ANOVA method where calculated F values were calculated to be lower in value than the theoretical ones showing that there was not significant difference between the proposed methods with exception of determination of ORP by using CLS and PLS models (Table 9, Tables S1 \& S2). The results of determination of ORP in PLS models demonstrated that there is a significant difference between Second derivative absorption spectra and all other absorption spectra while there is no significant difference between all other absorption spectra. Also, the results of determination of ORP in CLS models demonstrated that:

Table 9

\begin{tabular}{|c|c|c|c|c|c|c|c|c|c|c|c|c|c|}
\hline \multirow{2}{*}{$\begin{array}{l}\text { Spectra order } \\
\text { CLS }\end{array}$} & \multicolumn{3}{|c|}{ Zero } & \multicolumn{2}{|c|}{ First derivative } & \multicolumn{2}{|c|}{$\begin{array}{l}\text { Second } \\
\text { derivative }\end{array}$} & \multicolumn{2}{|c|}{ Ratio spectra } & \multicolumn{2}{|c|}{ Ratio derivative } & \multicolumn{2}{|c|}{$\begin{array}{l}\text { Ratio 2nd } \\
\text { derivative }\end{array}$} \\
\hline & Parameter & PAR & ORP & PAR & ORP & PAR & ORP & PAR & ORP & PAR & ORP & PAR & ORP \\
\hline \multirow{2}{*}{$\begin{array}{l}\text { Pharmaceutical } \\
\text { formulation }\end{array}$} & Mean & 100.07 & 101.38 & 98.90 & 103.91 & 116.24 & 114.08 & 100.11 & 100.68 & 99.66 & 100.74 & 110.60 & 105.42 \\
\hline & SD & 0.07 & 0.27 & 0.40 & 1.52 & 31.10 & 31.78 & 0.11 & 1.96 & 1.32 & 1.91 & 11.96 & 3.00 \\
\hline \multirow{2}{*}{$\begin{array}{l}\text { Standard } \\
\text { addition } \\
\text { technique }\end{array}$} & Mean & 100.16 & 100.50 & 99.40 & 104.14 & 102.65 & 109.53 & 100.31 & 100.60 & 100.63 & 100.40 & 110.48 & 102.63 \\
\hline & SD & 0.17 & 1.13 & 0.66 & 2.86 & 10.90 & 4.08 & 0.32 & 1.94 & 1.66 & 1.87 & 11.79 & 7.33 \\
\hline
\end{tabular}

For Zero order absorption: There is no significant difference between Zero absorption spectra \& all other absorption spectra except second derivative absorption.

For First derivative absorption: There is no significant difference between First derivative absorption spectra \& all other absorption spectra except Second derivative and Ratio spectra absorption.

For Second derivative absorption: There is significant difference between Second derivative absorption spectra \& all other absorption spectra except Ratio spectra absorption.

For Ratio spectra absorption: There is no significant difference between Ratio spectra absorption spectra \& all other absorption spectra except First derivative absorption and Ratio second derivative absorption.

For Ratio derivative absorption: There is no significant difference between Ratio derivative absorption spectra \& all other absorption spectra except Second derivative absorption.

For Ratio second derivative absorption: There is no significant difference between Ratio second derivative absorption spectra \& all other absorption spectra except Ratio spectra absorption and Second derivative absorption. 


\section{Conclusion}

Three chemometric models CLS, PLS and PCR can be used for simultaneous determination of PAR \& ORP in their mixture and pharmaceutical formulation. By applying different sets of data, we can deduce that different prediction powers are obtained from using different sets of data by manipulating the spectra in which first derivative set of data is best used for determination of both PAR \& ORP in CLS models and for determination of ORP in PLS models. Also, Zero absorption set of data is best used in determination of both drugs in PCR models and for determination of PAR in PLS models. Furthermore, we can deduce that PLS model has the most powerful prediction in determination of PAR \& ORP. On the other hand, Second derivative set of data has the least prediction powers in all models then Second derivative of ratio spectra set in all models so they can be neglected for PAR \& ORP determination in the future especially that they require more extra processing. Statistical comparison showed that there was no significant difference between the proposed methods except in case of determination of ORP in PAR \& ORP mixture by using CLS or PLS models. For CLS models, there is a significant difference between Second derivative absorption spectra \& all other absorption spectra except Ratio spectra, First derivative \& Ratio spectra, and Ratio spectra \& Ratio second derivative. For PLS models, Second derivative absorption spectra only shows significant difference with all other absorption spectra while all other absorption spectra don't behave.

\section{Declarations}

\section{Ethics approval and consent to participate}

Not applicable.

\section{Consent for publication}

Open access funding provided by The Science, Technology \& Innovation Funding Authority (STDF) in cooperation with The Egyptian Knowledge Bank (EKB).

\section{Availability of data and materials}

The authors confirm that the data supporting the findings of this study are available within the article [and/or] its Additional file.

\section{Competing interests}

The authors declare that they have no competing interests.

\section{Funding}

Not applicable.

\section{Author's Contributions}

Amr A. Mattar, Michael G. Fawzy, and Mahmoud M. Sebaiy designed and wrote the research work, and Sobhy M. El-Adl revised the manuscript and supervised the research. All authors read and approved the final manuscript.

\section{Acknowledgments}

The authors would like to thank Abdallah M. Hamdy, Teaching Assistant of Analytical Chemistry, Faculty of Pharmacy, Egyptian Russian University and express their gratitude feeling for his kindness, guidance, encouragement, and beneficial discussions that enriched our knowledge and help us in our work.

\section{Corresponding author}

Correspondence to Mahmoud M. Sebaiy.

\section{References}

1. M.M. Sebaiy, S.M. El-adl, A.A. Mattar, Different techniques for overlapped UV spectra resolution of some co-administered drugs with paracetamol in their combined pharmaceutical dosage forms, Spectrochim. Acta - Part A Mol. Biomol. Spectrosc. 224 (2020) 117429. doi:10.1016/j.saa.2019.117429.

2. M.M. Sebaiy, A.A. Mattar, Spectrum Subtraction Method for Simultaneous Determination of Paracetamol and Orphenadrine Citrate in Their Combined Pharmaceutical Dosage Forms. GSJ. 7 (2019) 1462-1468.

3. M.M. Sebaiy, A.A. Mattar, Q Absorbance Method for Simultaneous Determination of Paracetamol and Orphenadrine Citrate in Their Combined Pharmaceutical Dosage Forms. EUROPEAN JOURNAL OF PHARMACEUTICAL AND MEDICAL RESEARCH. 7 (2020) 464-468.

4. M.M. Sebaiy, A.A. Mattar, Absorbance Subtraction Method for Simultaneous Determination of Paracetamol and Orphenadrine Citrate in Their Combined Pharmaceutical Dosage Forms. Biomedical Journal of Scientific \& Technical Research. 25 (2020) 18987-18991. DOI: 10.26717/BJSTR.2020.25.004176

5. M.M. Sebaiy, A.A. Mattar, Isoabsorptive Point Method for Simultaneous Determination of Paracetamol and Orphenadrine Citrate in Their Combined Pharmaceutical Dosage Forms. Journal of Global Drugs and Therapeutics. 1 (2020) 1-4. DOI: 10.31487/j.GDT.2020.01.01. 
6. M.M. Sebaiy, A.A. Mattar, Ratio Subtraction coupled with Extended Ratio Subtraction Method for Simultaneous Determination of Paracetamol and Orphenadrine Citrate in Their Combined Pharmaceutical Dosage Forms. International Journal of Modern Pharmaceutical Research. 4 (2020) $40-44$.

7. M. Anas, A. Bashir, Simultaneous Determination of Orphenadrine Citrate and Paracetamol in Tablets by using RP- HPLC Coupled with UV Detection, Chem. Mater. Res. 9 (2017) 28-35.

8. D. Samson Israel, K. Krishna Chaitanya, D. Gowri Sankar, A. Vijayalakshmi, Method development and validation for simultaneous determination a multiple drug dosage form of Paracetamol, Orphenedrine, Ibuprofen by RP-HPLC, J. Glob. Trend. Pharm.Sci. 4 (2013) 1153-1162, 10 pp.

http://www.jgtps.com/admin/uploads/N71xng.pdf.

9. A. Nazir, Y. Naseer, S. Raza, R. Shahid, Development \& Validation of Analytical Method Used for Simultaneous Determination of Paracetamol, Caffeine and Orphenadrine Citrate By Hplc, in Pharmaceutical, Sci. Int. 28 (2016) 5215-5218.

10. Koppala Srinivasarao; Parsharamulu Rayam; An Indian Journal Full Paper, Anal. Chem. an Ind. J. 13 (2013) 69-76.

11. A.P.P. Eisele, D.N. Clausen, C.R.T. Tarley, L.H. Dall'Antonia, E.R. Sartori, Simultaneous Square-Wave Voltammetric Determination of Paracetamol, Caffeine and Orphenadrine in Pharmaceutical Formulations Using a Cathodically Pretreated Boron-Doped Diamond Electrode, Electroanal. 25 (2013) $1734-1741$. doi:10.1002/elan.201300137.

12. D.N. Haj-Ali, I.I. Hamdan, Development of a capillary electrophoresis method for the determination of orphenadrine citrate in tablets in the presence of paracetamol, Saud. Pharm. J. 18 (2010) 233-237. doi:10.1016/j.jsps.2010.07.007.

13. M.E. Bosch, A.J.S. Ruiz, C.B. Ojeda, Determination of paracetamol: Historical evolution, J. Pharm. Biomed. Anal. 42 (2006) $291-321$. doi:10.1016/j.jpba.2006.04.007.

14. P.C. Damiani, M.É. Ribone, C. Olivieri, Rapid Determination of Paracetamol in Blood Serum Samples by First-Derivative UV Absorption Spectroscopy, Anal. Lett. 28 (1995) 2219-2226. doi:10.1080/00032719508000040.

15. J.L. Vilchez, R. Blanc, R. Avidad, A. Navaln, Spectrofluorimetric determination of paracetamol in pharmaceuticals and biological fluids, J. Pharm. Biomed. Anal. 13 (1995) 1119-1125.

16. Y. Zhan, Y. Zhang, Q. Li, X. Du, Selective Spectrophotometric Determination of Paracetamol with Sodium Nitroprusside in Pharmaceutical and Biological Samples, J. Anal. Chem. 1, 66 (2011) 215-220. doi:10.1134/S1061934811020171.

17. A.M. Domínguez-ramírez, F.J. López-muñoz, J. Raúl, G. Alarcón, A. Desiree, L.A. Moreno-rocha, HPLC-PDA METHOD FOR THE QUANTIFICATION OF PARACETAMOL IN PLASMA: APPLICATION TO PK / PD STUDIES WITH ARTHRITIC RATS, Int. J. Pharm. Pharm. Sci. 9 (2017) $233-239$.

18. S.S. Narwade, Qualitative and Quantitative Analysis of Paracetamol in Different Drug Samples by HPLC Technique, J. Appl. Chem. 7 (2014) $46-49$.

19. D. Bose, A. Durgbanshi, Rapid Determination of Acetaminophen in Physiological Fluids by Liquid Chromatography Using SDS Mobile Phase and ED Detection, J. Chromatogr. Sci. 43 (2005) 313-318

20. R. Whelpton, K. Fernandes, K.A. Wilkinson, D.R. Goldhill, Determination of Paracetamol (Acetaminophen) in Blood and Plasma Using High Performance Liquid Chromatography with Dual Electrode Coulometric Quantification in the Redox Mode, Biomed. Chromatogr. 7 (1993) 4-7.

21. S.M.D.K.G. Senarathna, S.S. Ranganathan, N. Buckley, S.S.S.B.D.P. Soysa, A quick inexpensive laboratory method in acute paracetamol poisoning could improve risk assessment, management and resource utilization, Ind. J. Pharmacol. 44 (2012) 463-468. doi:10.4103/0253-7613.99305.

22. D. Mane, U. Kulkarni, K. Kulkarni, R. K. Pardeshi, Detection \& Identification of Paracetamol from biological material using HPTLC combined with Modern analytical technique, J. Med. Chem. Drug Discov. 2 (2016) 689-698.

23. C.C. Acta, B. Press, L.P. Hackett, L.J. Dusci, Short communication _ ..._, 74 (1977) 187-190.

24. C. Fernandez, Z. Heger, R. Kizek, T. Ramakrishnappa, Pharmaceutical Electrochemistry: the Electrochemical Oxidation of Paracetamol and Its Voltammetric Sensing in Biological Samples Based on Screen Printed Graphene Electrodes, Int. J. Electrochem. Sci. 10 (2015) $7440-7452$.

25. A.M. Santos, F.C. Vicentini, P.B. Deroco, R.C. Rocha-filho, Square-Wave Voltammetric Determination of Paracetamol and Codeine in Pharmaceutical and Human Body Fluid Samples Using a Cathodically Pretreated Boron-Doped Diamond Electrode, J. Braz. Chem. Soc. 26 (2015) $2159-2168$.

26. I. Navarro, E. Roldan, Determination of paracetamol in tablets and blood plasma by differential pulse voltammetry, J. Pharm. Biomed. Anal. 6 (1988) $969-$ 976.

27. M.A. Saracino, C. Petio, M. Vitali, L. Franchini, M.A. Raggi, Determination of orphenadrine plasma levels using HPLC with diode array detection and a novel solid-phase extraction procedure in psychiatric patients, J. Pharm. Biomed. Anal. 50 (2009) 501-506. doi:10.1016/j.jpba.2009.05.010.

28. W. Bilzer, U. Gundert-Remy, Determination of Nanogram Quantities of Diphenhydramine and Orphenadrine in Human Plasma Using Gas-Liquid Chromatography, Eur. J. Clin. Pharmacol. 270 (1973) 268-270.

29. M. Contin, R. Riva, F. Albani, A. Baruzzi, Simple and Rapid GLC Method for the Determination of Orphenadrine in Human Plasma, Biomed. Chromatogr. (1988) 193-194.

30. D. Lutz, W. Gielsdorf, H. Jaeger, Quantitative Determination of Diphenhydramine and Orphenadrine in Human Serum by Capillary Gas Chromatography, J. Clin. Chem. Clin. Biochem. 21 (1983) 595-597.

31. N. Sultana, M.S. Arayne, S.N. Ali, M.H. Zuberi, Simultaneous Determination of Paracetamol and Orphenadrine Citrate in Dosage Formulations and in Human Serum by RP-HPLC, Med. Chem. Res. 21 (2012) 2443-2448. doi:10.1007/s00044-011-9772-4.

\section{Figures}




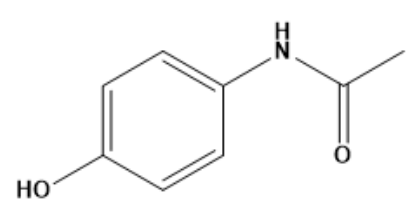

PAR

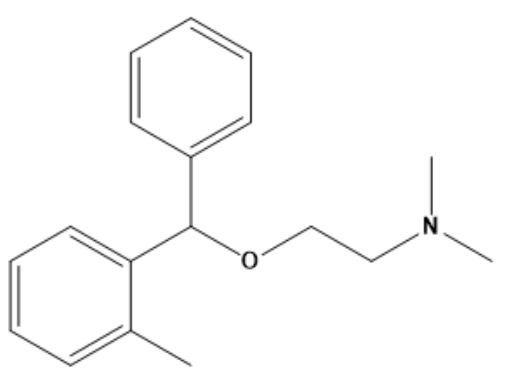

ORP

Figure 1

Chemical structures of paracetamol (PAR) and orphenadrine citrate (ORP).

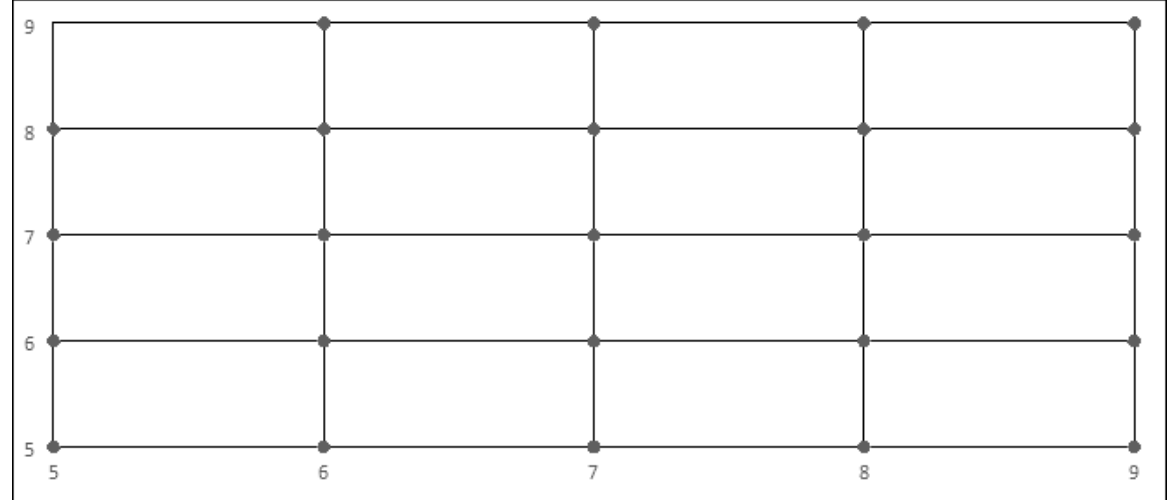

Figure 2

Concentration set design for PAR \& ORP for CLS, PLS and PCR methods. 
Zero Absorption set of data

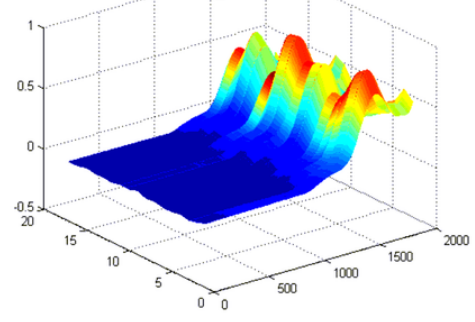

Second derivative set of data

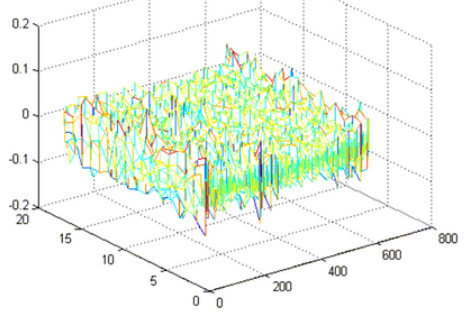

Ratio derivative set of data

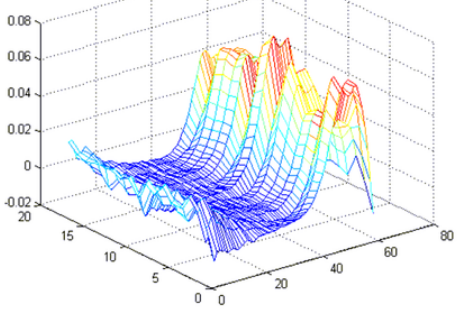

First derivative set of data

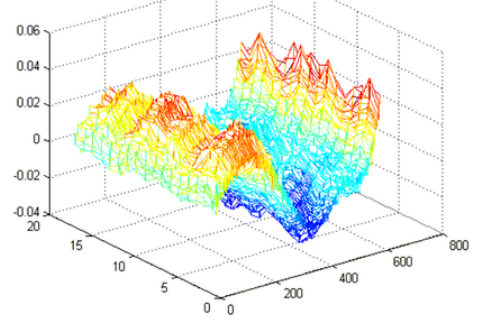

Ratio spectra set of data

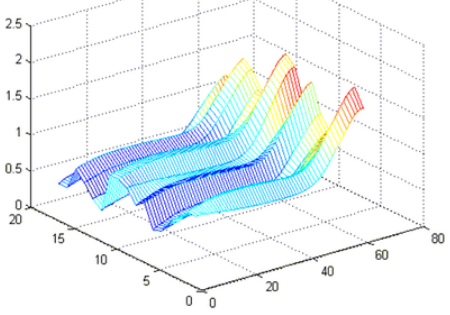

Ratio second derivative set of data

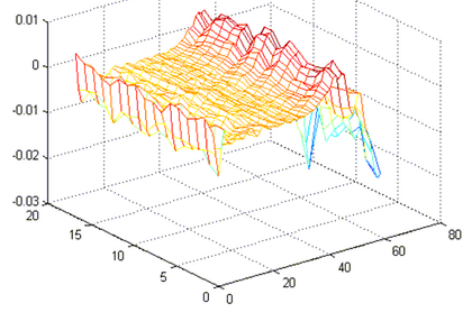

Figure 3

Different sets of data used for construction of CLS, PLS and PCR models. 

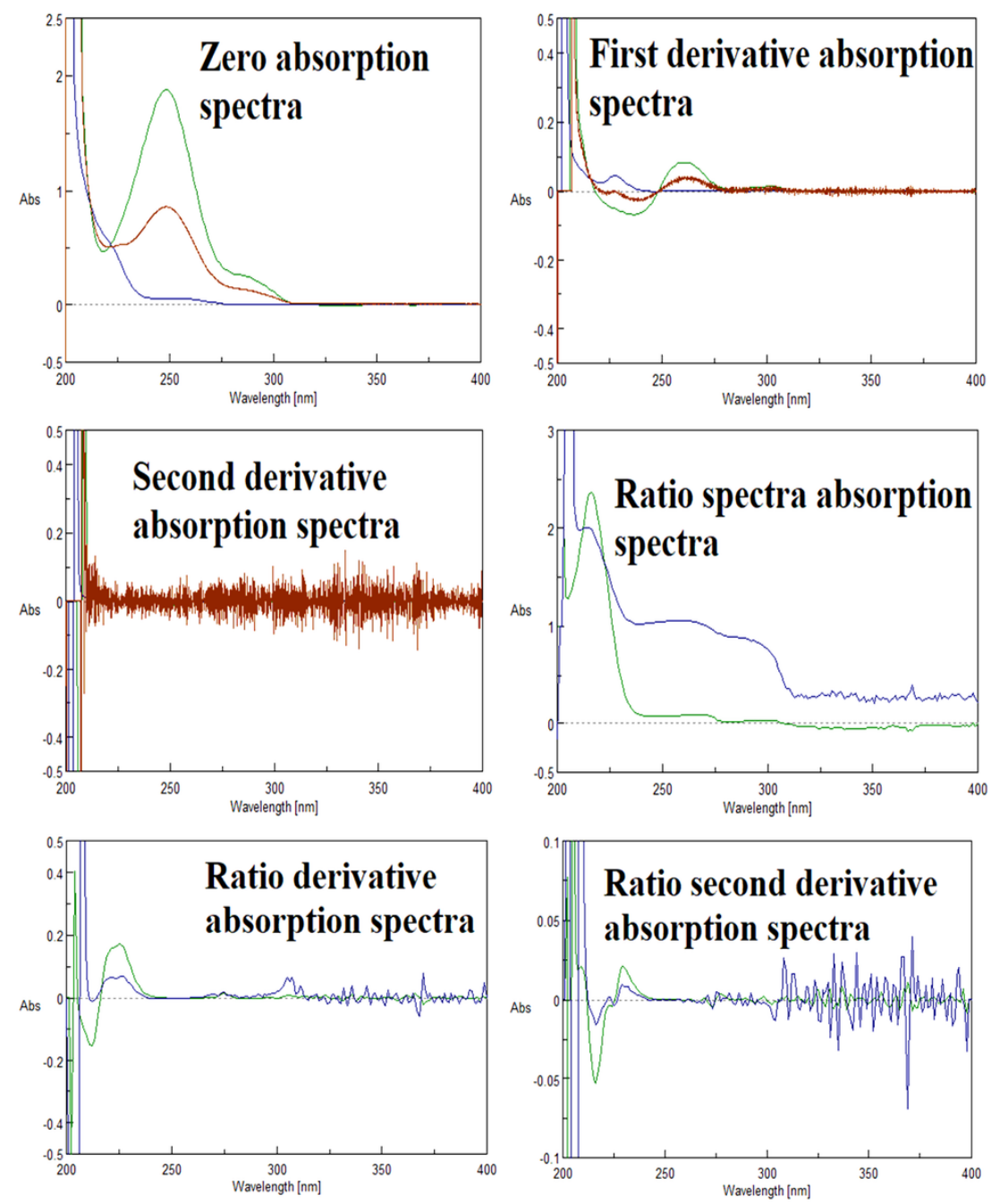

Figure 4

Different absorption spectra of PAR (20ug) \& ORP (20ug) and their mixture (9ug each). 

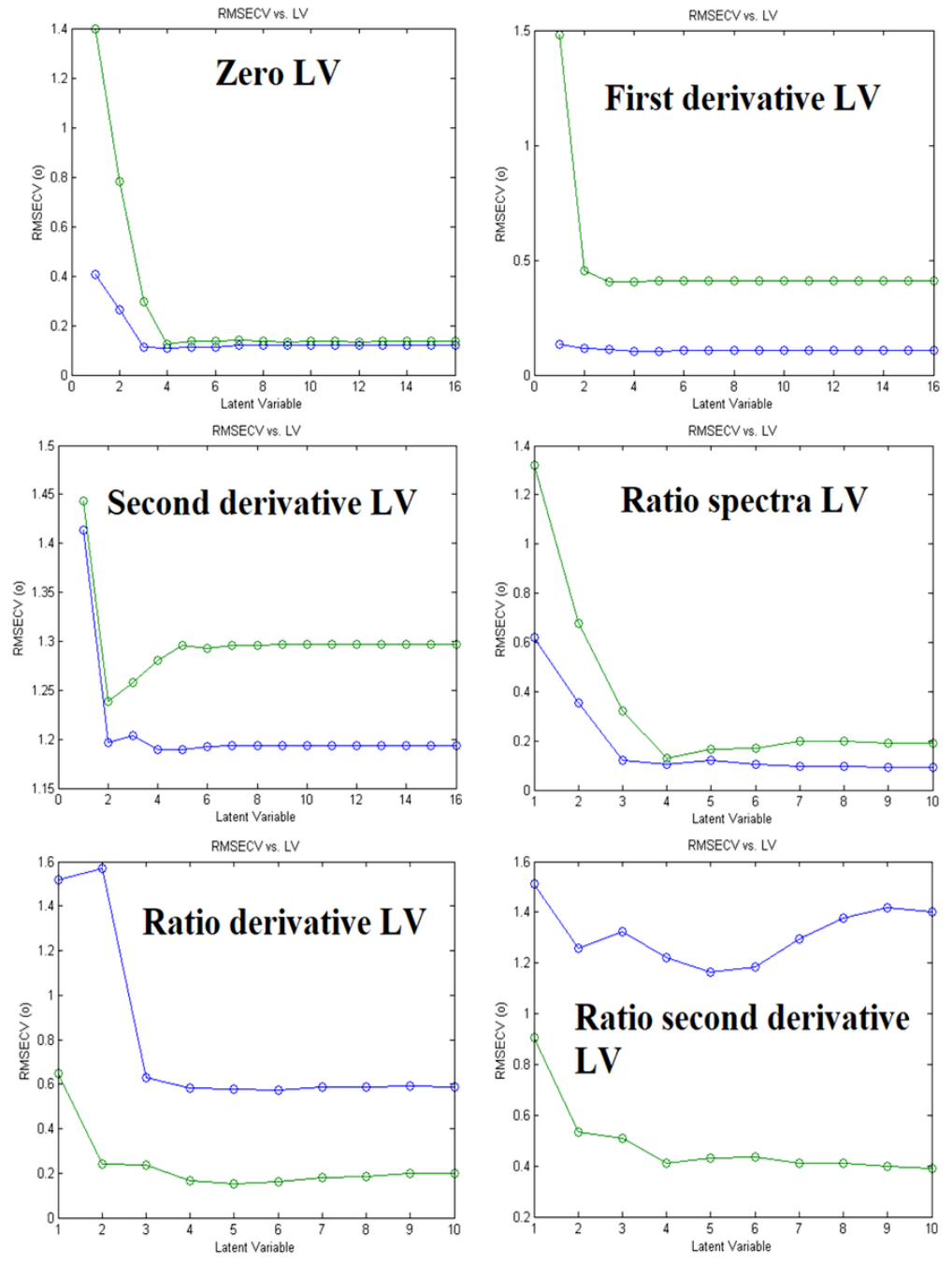

Figure 5

Different latent variables for different sets of data for construction of PLS models. 

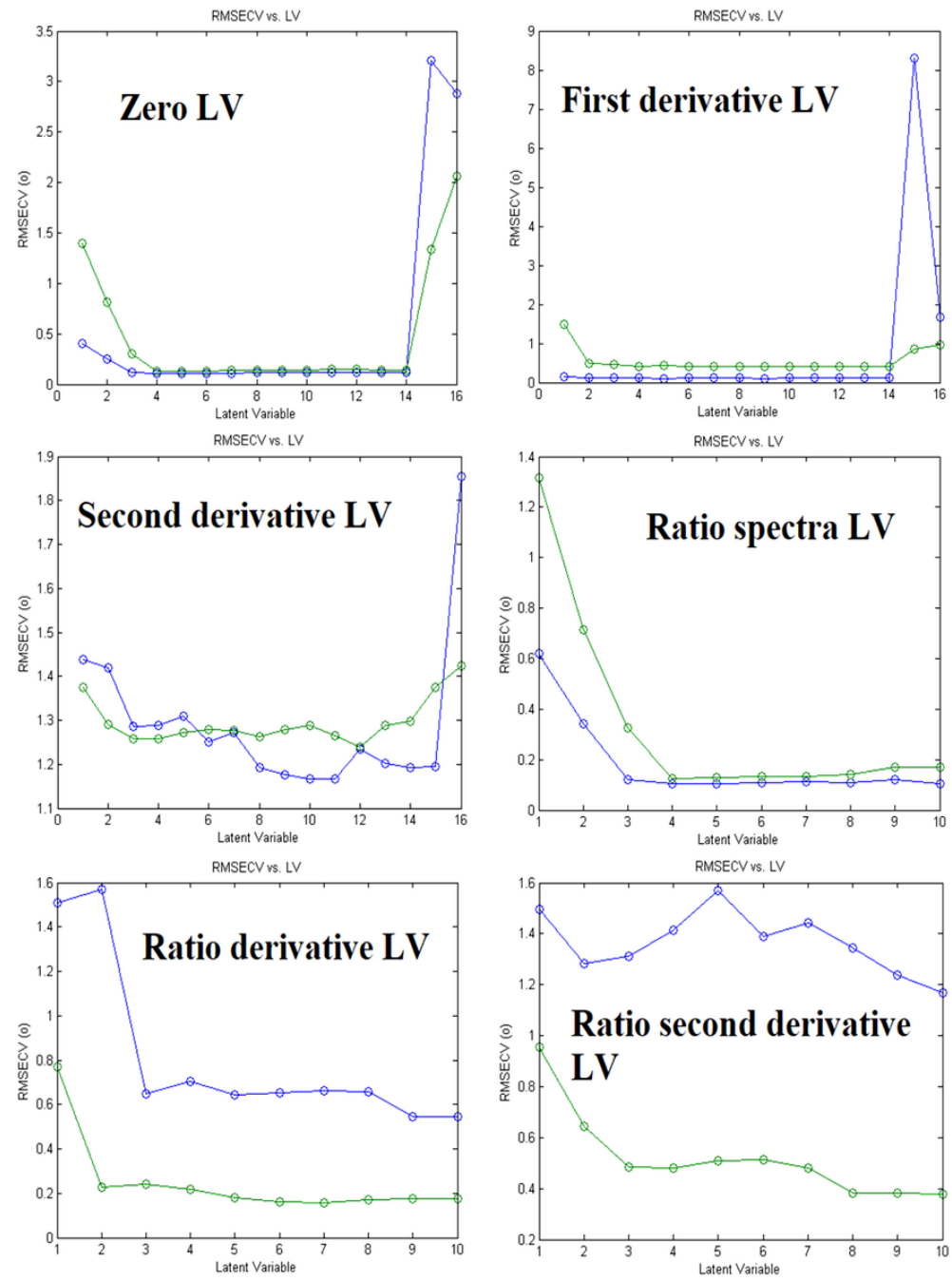

Figure 6

Different latent variables for different sets of data for construction of PCR models.

\section{Supplementary Files}

This is a list of supplementary files associated with this preprint. Click to download.

- GRAPHICALABSTRACT.docx

- Supplementaryfile.docx 